\title{
Zero Energy Buildings - With Special Reference to NZEBs in Kashmir, India
}

\author{
Er Irtiza Khurshid ${ }^{1}$, Zeeshan Altaf Beg ${ }^{2 *}$, Abrar Fayaz Aga ${ }^{3}$, Najmu Saqib Tantray ${ }^{4}$, \\ Umair Iqbal Mughal ${ }^{5}$, Sajid Majeed Mir ${ }^{6}$, Ashiq Hussain Bin Mushtaq ${ }^{7}$ \\ ${ }^{1}$ Assistant Professor, Department of Civil Engineering, SSM College of Engineering, Baramulla, India \\ 2,3,4,5,6,7 Student, Department of Civil Engineering, SSM College of Engineering, Baramulla, India \\ *Corresponding author: zeebeg1@gmail.com
}

\begin{abstract}
Amid the modern-day fluctuating energy prices, the impact on the climate and the statistics regarding the energy consumption, buildings are the main consumers in India. If the energy efficient methodologies are brought into the design procedures, the buildings so constructed will be future ready and highly efficient. The existing buildings will thus be a thing of the past and energy producing and low carbon footprint producing buildings will be achieved. Net Zero Energy Buildings (NZEB) are the buildings that will shape the futuristic societies and help us achieve what was previously thought to be impossible. These NZEBs will be the saviours of the environment and will represent the future of humanity. The NZEBs are all about the interconnectivity of the man-made environment and the ecosystem. With the future of the resources getting diminished day by day, the modern buildings need to be energy efficient as well as energy producing. In a NZEB, the total energy that is consumed is equal or sometimes less than the energy generated by renewable energy technologies installed on site. Multiple strategies are placed in to make the NZEB very efficient. In this paper, we tend to discuss the necessary arrangements that need to be deployed in Net Zero Energy Buildings in the Kashmir division of the UT of Jammu \& Kashmir, India.
\end{abstract}

Keywords: Interconnectivity, Saviour, Zero energy building.

\section{Introduction}

Imagine getting into your car, putting you key in ignition but nothing happens. Population of the world is growing exponentially to levels unimaginable. The biggest challenge that we will be facing is the exponentially growing population and the limited resources that our mother Earth has. Worst case scenario- shortage of food, lack of shelter and inevitable energy wars.

For solving this energy crisis, we have three primary options:

1. We can continue to exhaust the fossils fuels and that will lead to pollution of a very high scale which is not a good solution.

2. To use nuclear energy which eventually produces extremely dangerous nuclear waste. So, investing in this dangerous yet expensive plan is again not a good option.

3. Shifting our point of view to create energy rather than just using it. So, clean and green energy production is the answer which is fulfilled by the Zero Energy buildings.

Net zero energy quantifies the performance of building's energy, in which the buildings produces as much or more than energy than it requires to sustain all the operations. The two main aspects that define the net zero energy are the ability of the buildings to use the amount of energy it needs but it should also, during the year, produce enough energy equal to the consumption during that year and the other being the operations. In these buildings, all the elements are identified and selected in such a way that they provide maximum efficiency to the building and also the seasonal variations are also studied to make sure that nothing is missed and arrangements are made accordingly. The requirements including in depth discussion of the various elements of the NZEBs in the valley of Kashmir is the main target of this paper. be generated.

A net zero energy building requires a better design, the construction process and operation stages need to be perfectly coordinated and all these will be discussed in this paper regarding the NZEBS in India with special reference to Kashmir, the northern most part of the country.

Various articles have described Net Zero Energy Building but these regularly miss the understanding of the term "net zero". A building cannot be perfectly zero energy building, however, the fact that many buildings tend to use and produce energy thereby becoming self-sufficient are regarded as NZEBs.

There are many definitions for the Net Zero Energy Buildings but the U.S. Department of Energy (DOE) Building Technologies Program defines it as the building that has declined the energy desires significantly and the rest can be provided with the available renewable strategies.

\section{Background}

\section{A. Geography of India}

India is country with an area of about 3.28 million sq. kms and it is located in Southern part of Asia, having a long coastline of about $7600 \mathrm{kms}$ makes the country a huge peninsula as well. 
The country is also the seventh largest in the world in terms of the total area. It shares its border with Pakistan (NW), China, Nepal, Bhutan in the North, and Myanmar and Bangladesh in the North-East. The coastline is on the Arabian Sea, Bay of Bengal and the Indian Ocean. The country is divided into the Himalayan region, Northern plains, Deccan Plateau region and the Peninsular India.

\section{B. Climate of India}

South-West monsoon is most common in India transforming the climate into a monsoon type climate. The reversal of the surface winds in the South-West region of the country brings in the monsoon, turning the climate into a monsoon climate during June-September. The annual average rainfall all over India is around $1190 \mathrm{~mm}$ [1] but these figures vary from place to place. The rainfall is scarce in the western parts of the country i.e. Rajasthan which receives less than $140 \mathrm{~mm}$ of rainfall per year. The rainfall varies as one travels from North to South of the country.

\section{Solar Energy in India}

India is quite rich when it comes to solar energy resource. India receives around $200 \mathrm{MW} / \mathrm{sq}$. $\mathrm{km}$ of solar radiation on average. The total potential amounts to 657.4 million MWs when the entire area is considered but when it comes to solar site installation, only a part of the area can be put to use. This amounts to around 8 million MWs of energy which is equivalent to 6 mtoe (million tons of oil equivalent) per year if even only $9-10 \%$ land is used. This is all due to the agricultural land cover, forest cover and so on [2].

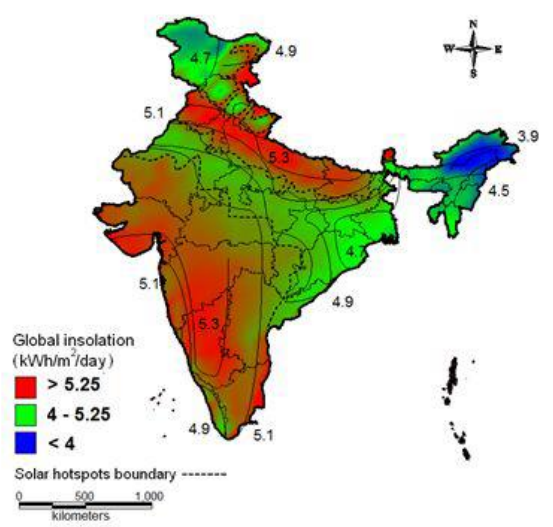

Fig. 1. Map depicting isohels and solar hotspots in India [4]

\section{Geography and Climate of Kashmir}

The Kashmir Division is a division of the Indian administered Union Territory of Jammu and Kashmir. The Kashmir division borders Jammu Division to the south. The division consists of the 10 districts: Baramulla, Budgam, Bandipore, Ganderbal, Anantnag, Kupwara, Kulgam, Pulwama, Shopian and Srinagar. Srinagar is the summer capital and the main city.

The rainfall is due to western disturbances and the south west monsoon and is about $27 \%$ of the total annual normal rainfall.
It is observed that the average annual rainfall is around 690 $\mathrm{mm} /$ year [3].

Table 1

Approx. wind speeds at Srinagar

\begin{tabular}{|c|c|}
\hline Wind speed in $\mathbf{~ k m} / \mathbf{h}$ & \\
\hline 1.7 & January \\
\hline 2.5 & February \\
\hline 2.9 & March \\
\hline 3.3 & April \\
\hline 3.0 & May \\
\hline 2.9 & June \\
\hline 2.7 & July \\
\hline 2.3 & August \\
\hline 2.1 & September \\
\hline 2.0 & October \\
\hline 1.7 & November \\
\hline 1.6 & December \\
\hline 2.4 & Annual \\
\hline
\end{tabular}

\section{Net Zero Energy Building}

\section{A. Definition of Net Zero Energy Building}

The buildings that are NZEBs have economic, social and environmental advantages. NZEBs provide us with new criteria of construction with high performance. These buildings are the representatives of a better quality of internal environment which also means a better quality of inhabitant's life. The NZEBS provide immense environmental benefits and also reduce the carbon footprint and the greenhouse gas emissions. This provides a solution for a better future that we are hoping for.

Usually, the net zero energy of the building determines its energy performance because a building is able to produce the amount of energy used by it during the year in operation. The main concept involved here is the initial consumption of fossil fuels or the nuclear fuels but later on this is compensated by production of energy during the year. The concept of zero energy is not that building energy consumes zero energy but it refers to the give and take process when it comes to the energy aspect. The NZEB consumes energy during a year but on the brighter side it also produces the energy.

\section{B. Net Zero Site Energy Building}

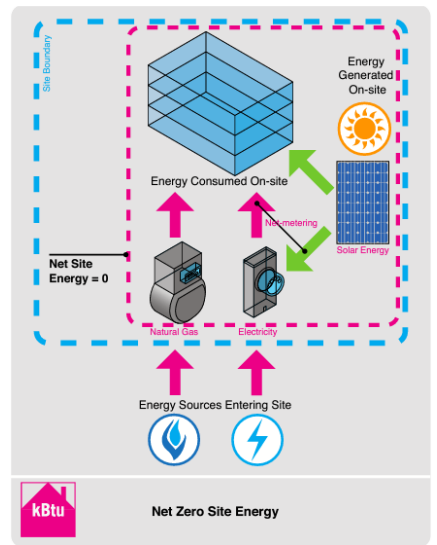

Fig. 2. Net Zero Energy Diagram (Hootman T, 2013) 
The site allocated for a Zero Energy Building is so much that it can generate the amount of energy that it is going to consume throughout the year. The measurement of the site can be done calculating the amount of energy within the said boundary.

This method is the conventional method and is mostly employed because we do not require the elements necessary for the measurement of other net zero energy measure.

\section{Requirements}

\section{A. Requirements}

Constructing a NZEB is a challenge that has to be dealt with precise calculations and all the elements are to be considered while the building is constructed. There are many requirements such as use of renewable energy, the passive solar heat, building envelope etc., which are to be taken consideration for gaining maximum efficiency if not $100 \%$. The below mentioned part deals with the requirements for a successful construction of the net zero energy building and also deals with each and every element such as windows, walls, roofs etc.

\section{B. Building massing- compactness (Low A/V Ratio)}

More heat is bound to escape to the outside area if the area of the external faces of the building is larger. So, in order to minimize the heat transfer through these faces, most compact design of the building has to be employed. Usually, the internal layout of a building determines its volume and this is directly linked to its ability to transfer the heat.

When heat losses are considered, the surface areas play a vital role. The building with a given volume, has its heat transfer ability and the heating required by it depends on the building envelope. It is observed that a building with smaller envelope requires less heating and while the ones with larger envelope will require more thermal insulation.

\section{Walls}

The thermal performance of the NZEB is immensely affected by the construction of walls. The fact that most of the energy escapes through the walls make it absolutely necessary to introduce walls that offer comfort and also achieve the goal of least transfer of heat through them. The walls also maintain the temperature range that is ideal for the building.

In Srinagar, the average annual temperature is $13.6^{\circ} \mathrm{C}$ or 56.5 ${ }^{\circ} \mathrm{F}$. Therefore, the building needs a heating system that has an ability to keep itself warm enough. The main objective of the insulation is not only to maintain the target temperatures that is primarily provided by the sun but it should also be able maintain the heat from the surrounding activities such as cooking, heat from inhabitants, lighting. In addition to all the properties mentioned above, the walls should also be able to maintain the acoustics of the building as well. At the top of all these properties/features, the walls need to maintain the building aesthetics which is one of the most important factors for a good building.

On all sides of a NZEB, insulation and the sealing are considered as these are the fundamentals of a NZEB. The insulation has to be applied in such a way that it fits the needs of all the surfaces.

\section{Roofs}

Roofs are the parts most exposed to the solar radiations and environmental change. So, roofs affect the internal comfort conditions which affects the inhabitants directly. The huge gain or loss of heat in buildings with large roof areas is due to this large area. Here, the U-value comes into play which determines the whether the thermal performance of a building is high or low. The thermal performance of the NZEB is increased by decreasing its U-value. U-Value is mathematically equal to the reciprocal of all resistances of the materials found in the building element. The two main types of roofs used are:

\section{Lightweight Roofs \\ 2. Photovoltaic Roofs}

\section{E. Windows}

Fenestration is the part of the building which refers to the openings such as windows. These are primarily concerned with the thermal comfort and are very vital for maintaining optimum lighting levels. Fenestrations are also very vital for the aesthetics of a building. But in the recent years, the glazing technologies have proved to be crucial for the windows in NZEBs. These glazing technologies have helped in maintaining the optimum internal temperature while adding aesthetics to the building. These technologies include aerogels, evacuated glazing, gas cavities etc.

The basic idea of the windows is to provide access to the daylight, Solar gain, passive security. For an efficient building, the optimization of the ratio between window and wall, so as to allow optimum daylight, solar gain meanwhile maintaining the optimum thermal performance as well. Glazing technology provides a very good solar gain during sunny days. The main purpose of energy efficient windows is:
1. Solar gain
2. Heat retention
3. Ventilation

\section{F. Doors}

One of the most commonly used doors in NZEB is the one with a core made up of polyurethane foam which is covered by a steel frame. This type of door has a magnetic strip which acts as the magnetic strip acts in a fridge and also weather stripping. There is no need to install more weather-strips if the above one is installed properly.

The R- values of the doors are a crucial factor for determining their insulation properties. Usually R-4 to R-6 are found to be the values of most of the steel and fiberglass doors. The important thing to notice here is the fact that such doors can offer a $400 \%$ increase in the insulation property as compared to a conventional solid wooden door. When we talk of the modern glass doors, these come with a plastic layer of insulation between the innermost and the outermost frames providing a 
very efficient thermal insulation. Moreover, the modern-day glazing technologies have been very efficient in providing variation in the thermal conductivity of the doors. These doors are very economical as well, and very useful in places of extreme temperature such as Kashmir.

The storm doors are also provided to increase the weather protection and also the overall efficiency of the NZEB. For the construction of a NZEB, a new and highly insulated and an energy efficient door needs to be installed because damaged or old doors may cause a decline in the insulation and energy efficiency. The following items can be considered to increase the energy efficiency of the door and of the building in general:

- Materials that have the ability to preserve greater values of insulation are used primarily for the cores.

- For the Weather stripping, we can use materials that are durable and perform better under extreme conditions as well;

- The materials which ensure the air leakage is minimized should also be employed;

- For framing, the materials which require least maintenance should be preferred; and

- A gap of about $10-12 \mathrm{~mm}$ is to be provided between the glazing of a double-glazed door, which improves the insulation and increases the thermal efficiency.

\section{G. Passive Solar heat gain}

When we talk of the concept of passive solar heat gain, we mean the use of the solar energy for the maintenance of the thermal comfort of the interior of the building. The use of solar energy for the purpose of heating and cooling the interior spaces of the building which is done by exposing them to the sun in such a way that optimal conditions are maintained. The solar radiation, when it strikes the building, is reflected as well absorbed depending upon the materials used for the thermal insulation of the building. The passive solar heat gain is based on a simple principle of absorbing and reflecting the solar radiation and it doesn't involve any mechanical or electrical instruments.

\section{H. Heat recovery ventilation}

The basic principle of the heat recovery ventilation is the movement of heat/mass from high temperature stream to a low temperature stream, the purpose being its use for more economical and easier way to maintain thermal conditions of the building. The heat/ mass when moves from one setup to another setup helps in maintaining the overall comfort of the building that too without using too many high-tech equipment. It is just the efficient or sustainable use of the heat that could've been lost otherwise. This whole process is technically termed as HRV or Heat Recovery Ventilation.

These systems (HRV) are vital as they are able to recover about $50-80 \%$ of the heat that could've been lost otherwise thus it increases the building's energy efficiency. There are numerous methods employed in NZEBs to recover the heat that can used later on and these include the rotary thermal wheel,
Heat pipes, run around method etc.

\section{Daylight harvesting}

One of the most important processes that take place in a NZEB is the daylight harvesting. There are two mechanisms that basically constitute the daylight:

- Skylight - in this mechanism, the light of the sky is the main source of the light

- Sunlight - wherein, the sun is the main of the light

A usual bright sunny day provides about 1-1.1 lac. Lumens / $\mathrm{m}^{2}$. At least $950 \mathrm{~m}^{2}$ could be lightened up at 950 lux, if the idea of daylighting was as much as $80-90 \%$ effective. The major challenge faced in every daylighting idea is the enhancement of distribution system's efficiency, thereby reducing the size of the collecting area. It is to be noted that no daylighting system exists with $100 \%$ efficiency. Henceforth, the size of the collecting area is proportional to the distribution system's efficiency.

The daylighting strategies are classified into two groups. In the first group, light is brought into the inside space of the building from the building's side. The common example of this is a Window. The second group includes top lighting systems, where the light enters the building space from the building's top. The simplest example of this is a Skylight. Thus, an effective daylighting strategy consists of the one which not only provides a radiant atmosphere for the dwellers but also makes the daylight levels paramount in the buildings.

\section{$J$. Use of On-site renewable energy}

Solar PV, wind and biofuels are the renewable energy sources that can be utilized on site. The other commonly used technologies are solar PV, solar hot water, small hydro units, biogas plants and sometimes wind turbines too. The energy system of the buildings directly utilizes the renewable energy used. The excess amount of energy can be stored in storage batteries. Small to medium sized buildings with large site areas and sufficient water supply of renewable sources justify the definition to a larger extent.

1) Solar Energy

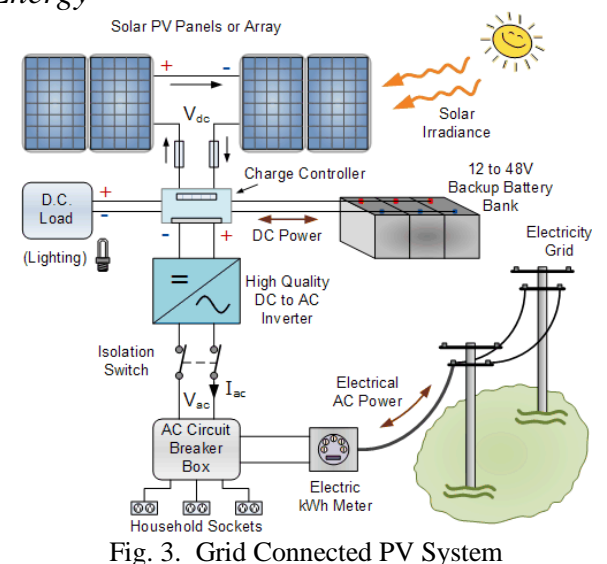

Fig. 3. Grid Connected PV System

i. Solar electricity generation system: The solar generation system is concerned with the generation of electricity on 
site for the use by the NZEB. The energy generated is consumed by the building for various operations.

ii. Grid-Tied PV: As the name suggests, the PV system that is connected to the electric grid system of the area is Gridtied PV.

iii. Off-Grid PV: This PV system takes in the solar energy from the PV panels and then supplies it to the inverters which in-turn provide electricity to the building.

2) Hydro Energy

i. Recommendations: Hydro energy can be can be used to produce electricity for the NZEB. The use of simple picohydropower project for a NZEB is enough to fulfill the energy demands.

\section{3) Biomass}

Since India has a good biomass energy potential therefore, it can be easily employed on site to produce some extra units of electricity and thus add more to the energy pool of the NZEB. By the process of biomass-gasification, enough energy can be provided to meet the household demands of cooking etc. In fact, small industries are capable of producing about $3 \mathrm{MW}$ of energy from biomass gasification process. Thus, this also proves to be vital in NZEB construction.

\section{K. Requirements for a cold climate zone such as Kashmir}

The climatic conditions and the geographical features of the Union Territory of Jammu \& Kashmir suggest many modifications pertaining to the design and construction of a NZEB (Net Zero Energy Building). The elements such as Building mass, HRS, Ventilation etc. are to be designed and installed according to the climatic conditions of the UT. The average temperature of Srinagar District, being low-moderate, suggests that the requirements need to be fulfilled in accordance with the Cold Climatic zones. The below mentioned requirements illustrate the requirements in Cold Climatic zones like Kashmir.

a. Building Mass: After thorough analysis, it is found that for the colder region of Kashmir, a combination of passive solar, mass construction and a good insulation offers best results. Thermal mass is able to absorb maximum heat during the sunny hours and save it for keeping the night space warmer.

b. Heat Recovery Systems: When it comes to Kashmir, it is required that a mechanical ventilation system is provided supporting the HRV to ensure comfort. Heat pipes can also be employed to conduct the heat of the soil to the floor surface.

c. Heating/Cooling convectors: These are very useful for heating/cooling of a small portion of the NZEB. All the rooms can be fitted with such convectors to ensure heating during winters which are very harsh in Kashmir (see figure 4).

d. Walls: The walls to be provided in the buildings have to withstand rough conditions and thus when made out of wood-based material should be properly insulated using materials like Glass wool which can prove be a material of choice. The material when sandwiched with the wall layers acts as a thermal insulator as well as maintains the acoustic properties of the buildings as well (see figure 5). This material is also very economical and can be available at Rs. 1100/ roll, the roll being of the length of about 10 feet. The companies currently providing good quality Glass wool are listed below:

\section{1) UP Twiga \\ 2) Phoenix}

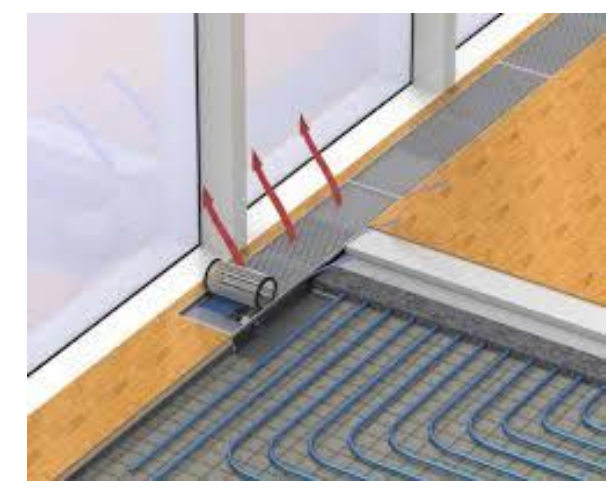

Fig. 4. Heating/Cooling convectors

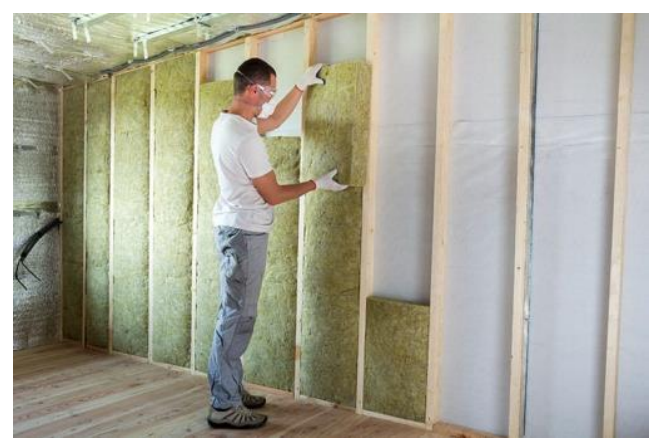

Fig. 5. Installation of thermal insulation in walls

e. Roofs: The roofs are most exposed to external conditions and in Kashmir these will be subjected to extreme cold weather during the months of Dec-Jan-Feb-Mar. The roofs installed need to be waterproof, high insulated on all sides in order to provide maximum efficiency. The material of choice here are the Solar reflective terrace tiles which are cost efficient and are water proof thus providing maximum benefits. These tiles can be either installed with solar panels on them providing solar energy for subsequent conversion to electrical energy or else can be used to plant variety of herbs and shrubs. The latter makes the roof a green roof which not only adds aesthetics to the building but also maintains the ecosystem around it. In addition to this, the green roof also acts a thermal barrier against the incoming solar radiations. Also, we can install solar roof tiles which are photovoltaics and serve the purpose of normal tiles as well.

$f$. Energy: Now shifting the focus to production of energy for use in NZEB, as energy production in Kashmir is a major issue, thus innovative methods need to be 
employed. Although the shift towards cleaner and greener buildings in Kashmir is not that evident but eventually, we observed that many basic techniques have already been in use at various levels whether it is use of Photovoltaics or Hydro power. Devices like solar inverters are readily available in Kashmir. Kashmir is also known for its good hydroelectric power potential. Current observations suggest that even when there is solid knowledge of NZEBs in Kashmir, some households have still managed to utilize hydro electrical energy by pico-hydropower projects. These provide a way forward for generation of electricity on site for the NZEBs in future.

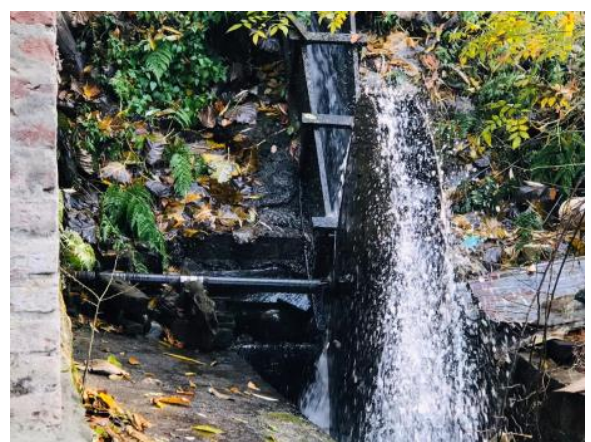

Fig. 6. Water wheel currently in use in various households in Kashmir

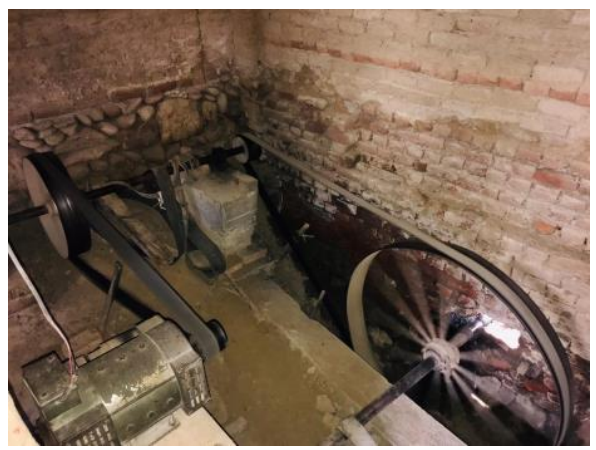

Fig. 7. Generator setup

\section{Requirements for the Hot and Humid part (Jammu)}

The regions of Jammu Division such the Jammu District, Udhampur, Kathua, Samba which exhibit moderate to high temperatures require different setups and various modifications are required to overcome the hot and humid weather. In addition to this, the rainy season in these areas is also of high intensity which also calls for modification in the building requirements of a NZEB.

Preventing the solar input is the primary function of the facade concept in hot and humid climatic conditions. SP coating has viability because in low altitude light attainment is ample throughout the year and there is absolutely no need for passive solar in winter. Generating solar energy is good on the west, east and south facades. The façade however needs to be supplied with thermal protection in order to prevent the transmission heat gains, thereby allowing the outward wall to absorb low amounts of radiation.

Rather than acting as thermal obstacles, walls primarily act as a screening against insects and remain flexible in wind penetration. Walls are least important in hot and humid climate.

The provision of foldable window-wall is a good solution. For thermal lag, light weight walls are the best as they re-radiate the heat at night and condense it in the morning. The deterioration of materials by moisture must be provided.

\section{Conclusion}

The pictures above depict a domestic hydro power project which, though being very basic technologically, is very useful for generating electricity on site for a NZEB. The hydro power project above, though being old, serves the purpose perfectly and for future buildings, such projects can be enhanced and put to use. The point of using these pictures is to convey that apart from various requirements of the buildings, the energy requirements can be fulfilled by enhancing the technologies of the present. Kashmir has a good potential to shift the focus from conventional "makkaans and buildings" to Net Zero Energy Buildings.

To conclude, there are many challenges that need to be dealt with proper strategies, but with modern day technology and proper planning and designing, it is absolutely possible to shift towards NZEBs in Kashmir as well. All the topics discussed and the methods already mentioned can be thrown into action to achieve the building of the Future, the saviour of coming generations - THE NET ZERO ENERGY BUILDINGS.

\section{References}

[1] http://www.indiaenergyportal.org/

[2] http://wgbis.ces.iisc.ernet.in/

[3] https://srinagar.nic.in/demography/

[4] https://www.nrel.gov/gis/solar.html 